\title{
JCEIB
}

Open Access; Volume 1 pp. 64-71; March2017

(C) Universiti Malaysia Pahang Publisher

DOI: https://doi.org/10.15282/JCEIB-V1-16.31/3/2017/1.1.1

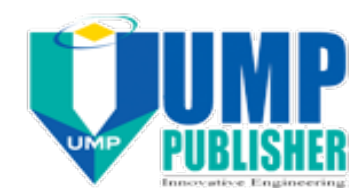

\section{EFFECT OF FERMENTATION TIME, MOISTURE CONTENT, AND TEMPERATURE ON SORBITOL PRODUCTION VIA SOLID STATE FERMENTATION PROCESS}

\author{
Zuriana Sidi Ahmad a , Mimi Sakinah Abdul Munaim ${ }^{\text {a,* }}$ \\ ${ }^{a}$ Faculty of Technology Engineering, University of Malaysia Pahang (UMP), \\ 26300,Kuantan Pahang, Malaysia \\ * Corresponding author: E-mail:mimi@ump.edu.my \\ Tel.: 09-5492825 Fax.: 09-5492662
}

\begin{abstract}
Malaysia is the largest country that has produced many types of waste. One of it is Meranti wood sawdust. These wastes result in a significant environmental problem if not dispose it in the proper manner. The main objective of this article is to produce the high yield of sorbitol by solid state fermentation (SSF) process from pretreated Meranti wood sawdust using bacterium Lactobacillus plantarum (BAA 793; NCIMB 8826). One factor at a time (OFAT) was studied for further process using solid state fermentation (SSF) process and investigated the effect of relevant parameters (fermentation time, range: 2 hours to 14 hours, moisture content, range: $40 \%$ to $90 \%$, temperature, range: $25^{\circ} \mathrm{C}$ to 45 ${ }^{\circ} \mathrm{C}$ ) to the solid-state fermentation (SSF) process in producing high yield of sorbitol. The highest product yield was obtained at 50\% moisture content, at 10 hours of fermentation time and $35^{\circ} \mathrm{C}$ of incubation temperature where the concentration of sorbitol was 25.68 $\mathrm{g} / \mathrm{L}$ respectively. This study also showed that the solid state fermentation (SSF) process will produce the high yield of sorbitol production compared to the submerged fermentation and could serve as a-low cost substrate for bioproducts production especially sorbitol
\end{abstract}

Keywords: Sorbitol; Lactobacillus plantarum; solid-state fermentation

\subsection{INTRODUCTION}

Solid state fermentation (SSF) is the cultivation of microorganism in the absence of free water under control conditions. SSF has been utilized to convert moist agriculture polymeric substrate like soy, rice, sawdust, wheat and other substrates into fermented food products including industrial enzymes, fuel, and nutrient enriched animal feeds. In the Asia and Latin America, solid state fermentation (SSF) has a traditional process in productions of food. In addition, SSF process is versatile enough to be used in a wide variety of biotechnological process (Pandey et al, 2001, 2004). The solid state particle not only acts as a substrate but also serves as an anchorage for the cell. (Swetha et al., 2006).

The processes of solid state fermentation (SSF) can involve pure culture of microorganisms or mixture of pure strains. In this research, solid state fermentation is preferred than liquid state fermentation/submerged fermentation, $\mathrm{SmF}$ because of simple technique, low waste water output (liquid waste is not produced) besides less chances of contamination, low capital investment (cheaper), lower levels of catabolite repression, 
better product recovery, less time consuming and high quality of production. In order to start the solid state fermentation process, many important aspects must be considered before proceed, such as selection of suitable microorganism and substrate, optimization of process parameters, isolation, and purification of product (Manpreet et al., 2005). Solid state fermentation (SSF) and submerged (liquid state) fermentation can be used to produce sorbitol.

Sorbitol or sometimes called as glucitol, is an alcohol sugar that found in nature at high concentration in many fruits such as berries, cherries, apple and others. It is sugar alcohol with 6 carbon structure and the molecular formula of $\mathrm{C}_{6} \mathrm{H}_{14} \mathrm{O}_{6}$. Normally, sorbitol is used in various food products because of health factors benefits. Sorbitol also has many applications such as in confectionary, chewing gums, candy, desserts, diabetics' food, ice cream and a wide range of food products. In addition, sorbitol also fulfills a role not only as a sweetener but also as a softener, humectants and a texturizer (Barros et al., 2006). In addition, the world market demand of sorbitol is increasing by constantly around $1-2 \%$ annually since the year 1997(Pedruzzi et al., 2007).

Sorbitol is produced by fermentative bacteria including Lactobacillus sp., Zymomonas mobilis, E.Coli and others of microorganisms. Some of the authors concluded that sorbitol is prebiotic (Sarmiento-Rubiano et al., 2007). Meranti wood sawdust is consisting of fine particles of wood (a waste product from the processing of wood) where it an important source of energy for various type of industries. Wood Sawdust such as Meranti type has well in the absorption capacity, porosity, and opacity and has low extractive content (Korpinan, 2010). Generally, Meranti wood sawdust or scientific name Philippine mahogany is an inexpensive material where it is also hardwood type and generally it is a common tree that presents all in a tropical country such as Malaysia. Meranti tree has widely used for making furniture and their waste like sawdust was use for heating in the boiler (Ahmad et al., 2009). Beside that, Meranti wood sawdust has three major components which are cellulose, hemicelluloses, and lignin content.

\section{Microorganisms}

\subsection{METHODS AND MATERIALS}

The microorganism that used for this study was Lactobacillus plantarum (BAA 793; NCIMB 8826) and was purchased from America type Culture Collection (ATCC). The Lactobacillus plantarum was maintained in MRS medium. The MRS agar and MRS broth were prepared according to the formula of Rogosa, Mitchell and Wiseman, (1951).

\section{Substrate}

The Meranti wood sawdust was obtained from Gambang Sawmill (M) Sdn Bhd, Gambang Kuantan, Pahang. The substrate that used in this study was glucose recovery after the process of pre-treatment Meranti wood sawdust and enzymatic hydrolysis. Then glucose in liquid form that produced using enzymatic hydrolysis will be converted to solid form using spray dryer and no moisture content of substrate after spray dried

\section{Solid state fermentation (SSF) process}

In the solid state fermentation process, several parameters play more important role in order to produce a high yield of sorbitol. For this part of OFAT study, the parameters such as fermentation time, moisture content and temperature were studied. The effect of fermentation time, moisture content and temperature on the sorbitol production were 
evaluated by varying the fermentation time from 2 hours to 14 hours, the moisture content of substrate from $40 \%$ to $90 \%$, and temperature of incubation from $25^{\circ} \mathrm{C}$ to $45^{\circ} \mathrm{C}$.

The inoculum was prepared in MRS broth (according to the formula of Rogosa, Mitchell and Wiseman, 1951). In this part, all the experiment should be conducted in laminar flow space in order to avoid contamination. $100 \mathrm{ml}$ of MRS medium was transferred into 250 $\mathrm{ml}$ Schott bottle and one loop full of bacteria (Lactobacillus plantarum) from agar plate was transferred into $100 \mathrm{ml}$ of MRS medium. After that, nitrogen gas $\left(\mathrm{N}_{2}\right)$ was purged into Schott bottle that was contained MRS medium and bacteria (Lactobacillus plantarum)in order to remove oxygen gas $\left(\mathrm{O}_{2}\right)$ inside Schott bottle and to maintain the anaerobic condition during cultivation process. Then, it was kept in the incubator at $30^{\circ} \mathrm{C}$. After 24hours cultivation, the optical density of inoculums was checked using UV-Vis Spectrophotometer. Setting the optical density at UV-Vis spectrophotometer equal to $600 \mathrm{~nm}\left(\mathrm{OD}_{600}\right)$. The values of $\mathrm{OD}_{600}$ should be less than 0.4 or $(0.1-0.2)$ (Sabu et al., 2006)

Two grams of samples was entered into a $50 \mathrm{ml}$ Erlenmeyer conical flask, then it will be moistened with $50 \%$ of distil water (Sabu et al., 2006). Then, $\mathrm{pH}$ of samples was maintained with $\mathrm{pH} 5$ because bacteria of Lactobacillus Plantarum have optimum growth at pH5. All the apparatus and materials were sterilized at $121{ }^{\circ} \mathrm{C}$ for 15 minutes in order to avoid from contaminations. Then, this experiment must be conducted in a laminar flow to avoid contamination and loss of viability. After the sterile process, the samples should be cooled. After that, the inoculums were entered into the samples where the sample was inoculated with $10 \%$ of inoculums. Then, samples were purged with nitrogen gas $\left(\mathrm{N}_{2}\right)$ inside conical flask to replaced oxygen gas to maintain the anaerobic condition. Then it was incubated at $30{ }^{\circ} \mathrm{C}$ for 10 hours. In this part of the experiment, which varies only one factor or variable at a time and while keeping others parameter fixed. Then all the experiments were carried out in 3 sets to get the average values.

\section{Analysis methods}

The sorbitol production was determined using High-Performance Liquid Chromatography, (HPLC Agilent, 1200 series). The column for the quantification of sorbitol was Rezex Chromatographic Method, RCM Monosaccharides 300 X $7.8 \mathrm{~mm}$ with water as a mobile phase. The sugar was eluted with deionized water at a flow rate $0.6 \mathrm{~mL} / \mathrm{min}$ and the column, maintained at $75{ }^{\circ} \mathrm{C}$ with the retention time is $30 \mathrm{~min}$. This method used Refractive Index, RI as a detector (Saha and Nakamura, 2003).

\section{Effect of Fermentation Time on Sorbitol Production \\ 3.0 RESULTS AND DISCUSSION}

Figure 1 showed the effect of fermentation time to the sorbitol production. From the Figure 1, the sorbitol production was slowly at the starting point and then increased smoothly with the optimum time was about 10 hours which is, the sorbitol production was $27.73 \mathrm{~g} / \mathrm{L}$ respectively after fixed the temperature at $30{ }^{\circ} \mathrm{C}$ and moisture content $50 \%$. This is because of the bacteria already optimum interacted with the substrate at 10 hours. Then, after 10 hours, the production of sorbitol slowly decreased at 12 hours until 14 hours. This is because the bacteria were starting to inactive at that point in solid state condition, that why the sorbitol production was low after 10 hours reaction time. 


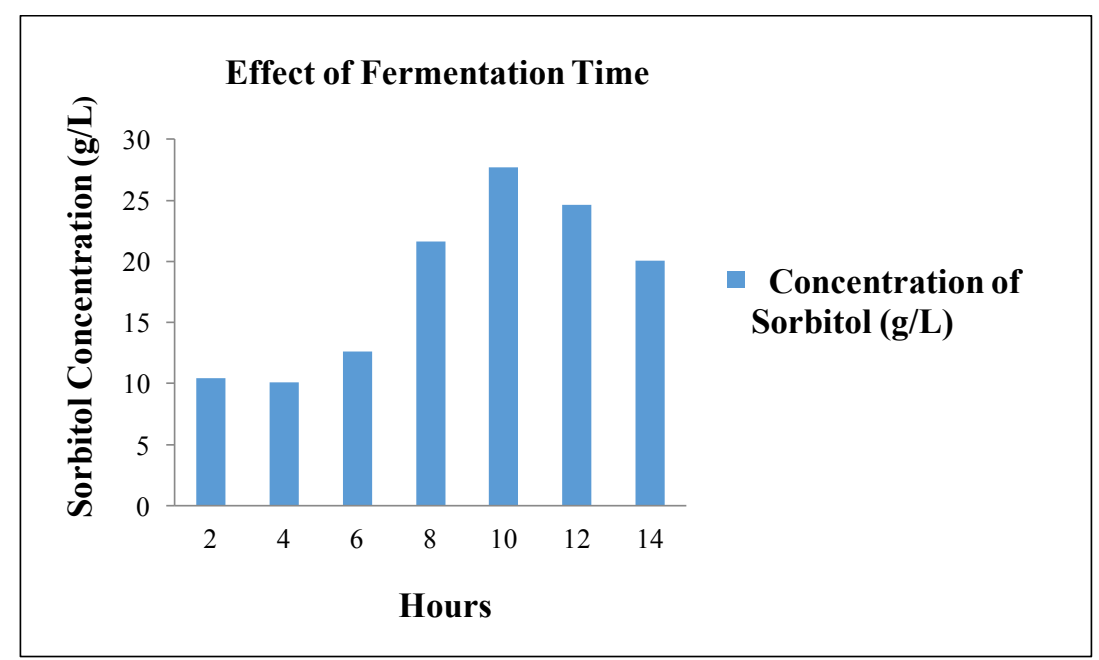

Figure 1: Effect of fermentation time in SSF process

\section{Effect of Moisture Content on Sorbitol Production}

Figure 2, shown the result of OFAT study for the effect of moisture content in solid state fermentation (SSF) process using glucose pretreated from Meranti wood sawdust (after enzymatic hydrolysis process). From the result, the moisture content in solid state fermentation was quite important and it depends on the type of microorganism and substrate that used in the solid state fermentation process. From the graph, 50\% will give optimum production of sorbitol, where the product was about $20.0 \mathrm{~g} / \mathrm{L}$ after fixed the temperature at $30^{\circ} \mathrm{C}$ and fermentation time at 10 hours. Then, the increment of sorbitol production from $40 \%$ to $50 \%$ was about $7.5 \%$. This means that the formation of some products such as sorbitol will be influenced by water activity where the optimal moisture content depends on the cultivation temperature and optimal growth of Lactobacillus plantarum NCIMB 8826. Then, it can be proved from the equation below of wateractivity-based growth dependence (Barbara et al., 2006):

$\mu_{\mathrm{FW}}=1.053 \exp \left(-131.6 \mathrm{aw}^{3}+94.99 \mathrm{aw}^{2}+214.219 \mathrm{aw}-177.668\right)$

Where $\mu_{\mathrm{FW}}=$ Fractional specific growth rate based on water activity and aw $=$ Fermenting solid water activities

The $60 \%$ of moisture content will give about $11.50 \mathrm{~g} / \mathrm{L}, 70 \%$ was about $12.50 \mathrm{~g} / \mathrm{L}, 80 \%$, and $90 \%$ gave about $11.90 \mathrm{~g} / \mathrm{L}$ and $8.50 \mathrm{~g} / \mathrm{L}$ of sorbitol production respectively. The production of sorbitol was decreased after moisture content level high. This is because bacteria Lactobacillus plantarum NCIMB 8826 was not active to react in high moisture content of substrate and that why the water activity also was important to produce a high yield of sorbitol. The equation of moisture content was shown as below:

$\mathrm{MC}=($ Weight of water/ Weight of samples $) \times 100 \%$

In addition, the moisture content also has relations with water activity $\left(a_{w}\right)$ and relative humidity $(\mathrm{RH})$. Actually, the water activity $\left(\mathrm{a}_{\mathrm{w}}\right)$ of the moist solid substrate is the ratio of the vapor pressure of water above the substrate in the close system to the vapor pressure 
of the pure water at same temperature. For the pure water, the water activity $\left(\mathrm{a}_{\mathrm{w}}\right)$ has 1.0 and $\mathrm{a}_{\mathrm{w}}$ will decrease after addition with solutes. The water activity $\left(\mathrm{a}_{\mathrm{w}}\right)$ is measured by relative humidity divided by 100 (Manpreet et al., 2005). The equation for water activities and relative humidity was showed below:

$\mathrm{a}_{\mathrm{w}}=\mathrm{p} / \mathrm{po}=\% \mathrm{RH} / 100$

Where, the $\mathrm{p}=$ Vapor pressure of water in above the substrate, po $=$ Vapor pressure of water at the same temperature and $\mathrm{RH}=$ relative humidity.

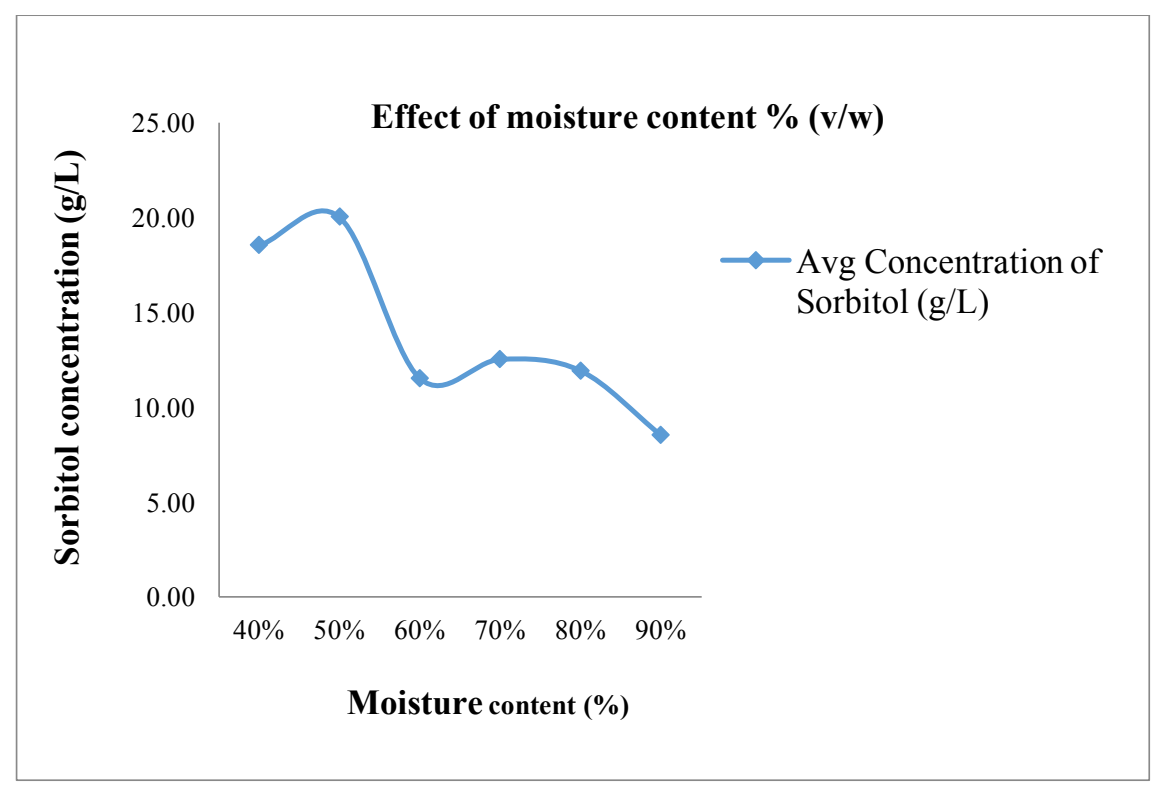

Figure 2: Effect of moisture content in SSF process

\section{Effect of Temperature on Sorbitol Production}

Then, for the effect of temperature on sorbitol production, shows in Figure 3 . The formation of some products will be influenced by water activity where the optimal moisture content depends on the cultivation temperature. Therefore, the temperatures in the SSF process will be rise rapidly because of the quantity of water in the substrate are very low to absorb the heat. The optimal temperature that used in the SSF process for growth microorganism around $20{ }^{\circ} \mathrm{C}$ and $40{ }^{\circ} \mathrm{C}$ and the temperature below then $50{ }^{\circ} \mathrm{C}$ prefer for maximum growth (Manpreet et al., 2005).

For this study, the range of temperature that used was $25{ }^{\circ} \mathrm{C}$ to $45{ }^{\circ} \mathrm{C}$ in order to check the optimum point of temperature for sorbitol production while the moisture content and fermentation time were maintained at $50 \%$ and at 10 hours. The graph plotted from 3 shows that the starting temperature at $25{ }^{\circ} \mathrm{C}$, was given the low of sorbitol production which is about $11.16 \mathrm{~g} / \mathrm{L}$ and the production of sorbitol was increased at temperature $30^{\circ} \mathrm{C}$ where the product was about $25.45 \mathrm{~g} / \mathrm{L}$ and at $35{ }^{\circ} \mathrm{C}$. Then, the temperature at $35{ }^{\circ} \mathrm{C}$ was given the high yield of sorbitol, where the concentration was about $25.68 \mathrm{~g} / \mathrm{L}$. This is because, the bacteria of Lactobacillus plantarum NCIMB 8826 was optimum reacted with the substrate at that temperature $\left(35^{\circ} \mathrm{C}\right)$, that why the production of sorbitol was higher at that point. 
Generally, the amount of metabolic heat produced in the SSF process by microbial growth around $100-300 \mathrm{KJ}$ of heat per $\mathrm{Kg}$ of cell mass (Prior et al., 1992). The production of sorbitol was decreased start at $40{ }^{\circ} \mathrm{C}$ until $45{ }^{\circ} \mathrm{C}$ because of the bacteria Lactobacillus plantarum NCIMB 8826 was loose of viability and destroyed by lysis, and that why the sorbitol production was low at that point where the products were about $24.76 \mathrm{~g} / \mathrm{L}$ and $17.56 \mathrm{~g} / \mathrm{L}$ respectively. In addition, the effect of temperature for this SSF can be proved by Arrhenius equation where the effect of temperature on both specific growth rate and the specific death rate has been well described by Arrhenius equation (Manpreet et al., 2005). The equation has shown as below:

$\mu \mathrm{m}=\mu \mathrm{mo} \exp (-\mathrm{Eg} / \mathrm{RT})-\mathrm{D}_{\mathrm{o}} \exp (-\mathrm{Ed} / \mathrm{RT})$

Where, $\mathrm{R}$ is universal gas constant, $\mathrm{T}$ is the absolute temperature, Eg and Ed are the activation energies for growth and death, $\mu \mathrm{m}$ and $\mu \mathrm{mo}$ are specific growth rate and specific death rate, respectively. And others Arrhenius equation:

$\mathrm{K}=\mathrm{Ae}^{-(\mathrm{EA} / \mathrm{RT})}$

$\ln \mathrm{K}=\ln \mathrm{A}-\mathrm{EA} / \mathrm{RT}$

Where $\mathrm{K}$ is rate constant, $\mathrm{A}$ is frequency factor/ pre-exponential factor, $\mathrm{EA}$ is activation energy $\mathrm{R}$ is the gas constant and $\mathrm{T}$ is the temperature in Kelvin unit. The Arrhenius equation used to show the effect of a change of temperature on the rate constant and therefore on the rate of the reaction. For example, the temperature increase from $30{ }^{\circ} \mathrm{C}$ to $35^{\circ} \mathrm{C}$ the rate constant and rate of reaction will change. The frequency factor $\mathrm{A}$, in the equation is approximately constant for such a small temperature change.

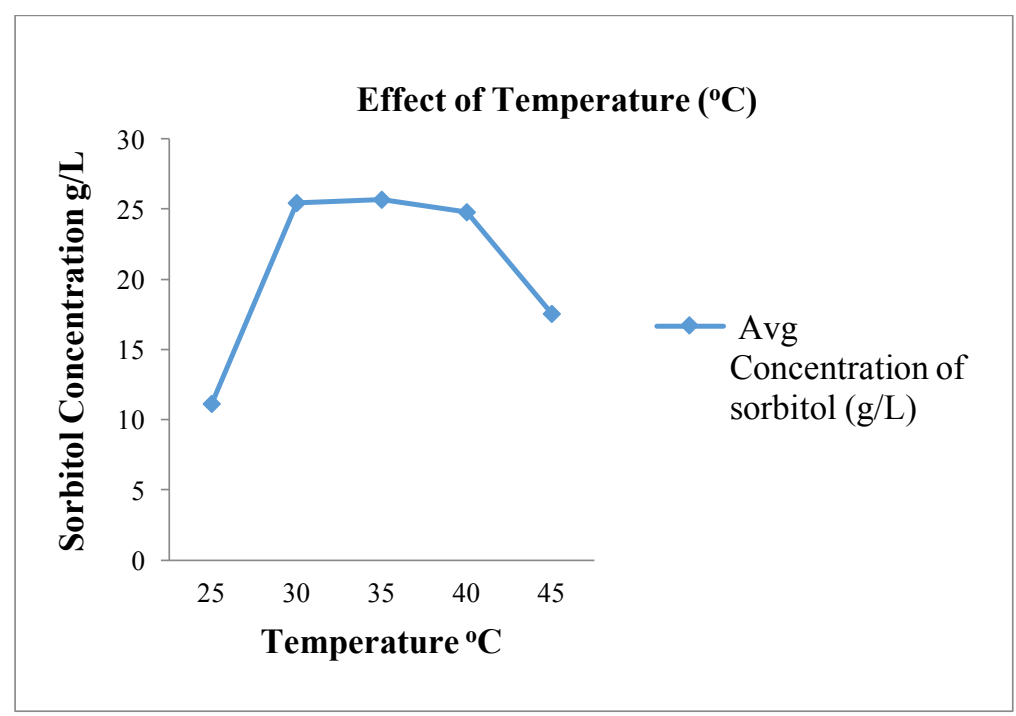

Figure 3: Effect of temperature in SSF process

\subsection{CONCLUSIONS}

In conclusion, solid state fermentation (SSF) process will produced the high yield of sorbitol production $(25.68 \mathrm{~g} / \mathrm{L})$ compared to the submerged fermentation $(61.66 \mathrm{mg} / \mathrm{L})$ from the previous researcher. Beside that, the parameters (fermentation time, moisture 
content and temperature) that influencing sorbitol production by SSF process should be controlled in order to get the high yield of sorbitol.

\section{ACKNOWLEDGEMENT}

The authors thank the support of Faculty of Technology Engineering, University Malaysia Pahang (UMP) for providing the facilities.

\section{REFERENCES}

Ahmad, A., Rafatullah, M., Sulaiman, O., Ibrahim, M.H. and Hashim, R. (2009). Scavenging Behavior of Meranti Sawdust in the Removal of Methylene Blue from Aqueous Solution. Journal of Hazardous Materials, 170:357-365.

Barbara, W., Graves, S.A., Dejoy, A. and Penelope, P. (2006). Maternal Body Mass Index, Delivery Route, And Induction Of Labor In A Midwifery Caseload. Journal of Midwifery and Womens Health, 51: 254-59.

Barros, M.D., Celligoi, M.A.P.C., Vignoli, J.A. and Vargas, L.H.M. (2006). Influence of Ultrasound on Sorbitol Release by Zymomonas mobilis Grown on High Sucrose Concentration. An International Journal Brazilian Archives of Biology and Technology, 49: 371-374.

Korpinen, R. (2010). On the Potential Utilisation Of Sawdust and Wood Chip Screenings On The Potential Utilisation of Sawdust And Wood Chip Screenings. Ph. D. Thesis. Abo Akademi University, Finland.

Manpreet, S., Sawraj, S., Sachin, D., Pankaj,S., and Banerjee, U.C.(2005). Influence of Process Parameters on the Production of Metabolites in Solid- State Fermentation. Malaysian Journal of Microbiology, 1(2): 1-9.

Pandey, A., Soccol, C. R., Rodriguez-León, J. A. and Nigam, P. (2001). Production of Organic Acids by Solid-State Fermentation. In: Solid-State Fermentation In Biotechnology -Fundamentals and Applications, p.113-126. New Delhi: Asiatech Publishers

Pandey, A, Trivedi, P., Kumar, B., Chaurasia, B., Singh, S. and Palni, L.M.S.(2004). Development of Microbial Inoculants For Enhancing Plant Performance In Mountains. In: Reddy, M.S., Khanna, S., (eds). Biotechnological Approaches for Sustainable development. Allied Publishers Pvt.Limited, New Delhi, pp. 13-20.

Pedruzzi, I., Eloane, M., Vera, G.M., Eduardo, A.B.S., Mauricio, M.S., and Rodrigues, A.E. ( 2007).Quantification of Lactobionic Acid and Sorbitol from Enzymatic Reaction of Fructose and Lactose By High-Performance Liquid Chromatography. Journal of Chromatography A, 1145:128-132.

Prior, B.A., Du Prezz, J.C. and Rein, P.W. (1992). Environmental Parameters in Doelle, H.W., Mitchell D.A.and Rolz, C. (eds) Solid Substrate Cultivation, London: Elsevier, p.65-85.

Rogosa, M., Mitchell, J. A. and R. F. Wiseman, R.F. (1951). A Selective Medium for The Isolation and Enumeration Of Oral And Fecal Lactobacilli. Journal of Bacteriol, 62:132.

Sabu, A., Swati, C., and Pandey, A. (2006). Tannase production by Lactobacillus sp. ASR-SI Under Solid State Fermentation. Process Biocheistry, 41: 575-580.

Saha, B.C and Nakamura, L.K.. (20030. Production of Mannitol and Lactic acid by Fermentation with Lactobacillus intermedius NRRL B-3693†. Biotechnology And Bioengineering, 39: 991-995. 
Sarmiento-Rubiano, L.Z., Zuniga, M., Perez-Martinez, G., Yebra, M.J. (2007). Dietary Supplimentation With Sorbitol Results in Selective Enrichment of Lactobacilli in Rat Intestine. Research in Microbiology, 158: 694-701.

Swetha, S., Dhanya, G., Kesavan, M.N., Carlos, R., and Pandey, A. (2006). a-Amylases from Microbial Sources-An Overview on Recent Developments. Journal of Food Technol. Biotechnol, 44:173- 184. 